See Article page 74 .

\section{Commentary: Mobilizing the reserves in coronary artery bypass grafting with and without fractional flow}

\author{
Torsten Doenst, MD, PhD, Mahmoud Diab, MD, \\ Gloria Faerber, MD, and Markus Richter, MD
}

Ever since the introduction of percutaneous coronary intervention (PCI) for the treatment of chronic coronary artery disease (CAD), there has been hope of curing CAD mechanically without exposing the patient to much more invasive coronary artery bypass surgery (CABG). Hefty controversies have created somewhat of a "battlefield of PCI and CABG" (see the EXCEL trial data controversy ${ }^{1}$ ), where different guideline interpretations and possibly other incentives resulted in ratios of PCI to CABG performance ranging from approximately $2: 1$ in one country to more than 10:1 in the next. ${ }^{2}$

From a patient perspective, such differences should be acceptable only if treatment effects are similar. However, results may differ significantly, ${ }^{3}$ and we recently suggested that $\mathrm{CABG}$ and PCI differ in their mechanisms. ${ }^{4} \mathrm{CABG}$, in addition to revascularizing chronically ischemic myocardium, provides protection against new myocardial infarctions by creating "surgical collaterals." Collaterals can prevent infarctions if a proximal coronary lesion causes vessel occlusion. This infarct preventative effect appears to be responsible for the survival effect of invasive CAD therapy. ${ }^{4}$ Since most infarct-causing lesions are not stented, CABG's advantage over PCI

\footnotetext{
From the Department of Cardiothoracic Surgery, Friedrich-Schiller University Jena, University Hospital, Jena, Germany.

Disclosures: The authors reported no conflicts of interest.

The Journal policy requires editors and reviewers to disclose conflicts of interest and to decline handling or reviewing manuscripts for which they may have a conflict of interest. The editors and reviewers of this article have no conflicts of interest.

Received for publication Nov 23, 2020; revisions received Nov 23, 2020; accepted for publication Nov 27, 2020; available ahead of print Jan 5, 2021.

Address for reprints: Torsten Doenst, MD, PhD, Department of Cardiothoracic Surgery, University of Jena, Am Klinikum 1, 07747 Jena, Germany (E-mail: doenst@med.uni-jena.de).

JTCVS Open 2021;5:83-4

2666-2736

Copyright (C) 2020 The Authors. Published by Elsevier Inc. on behalf of The American Association for Thoracic Surgery. This is an open access article under the CC BY-NCND license (http://creativecommons.org/licenses/by-nc-nd/4.0/).

https://doi.org/10.1016/j.xjon.2020.11.013
}

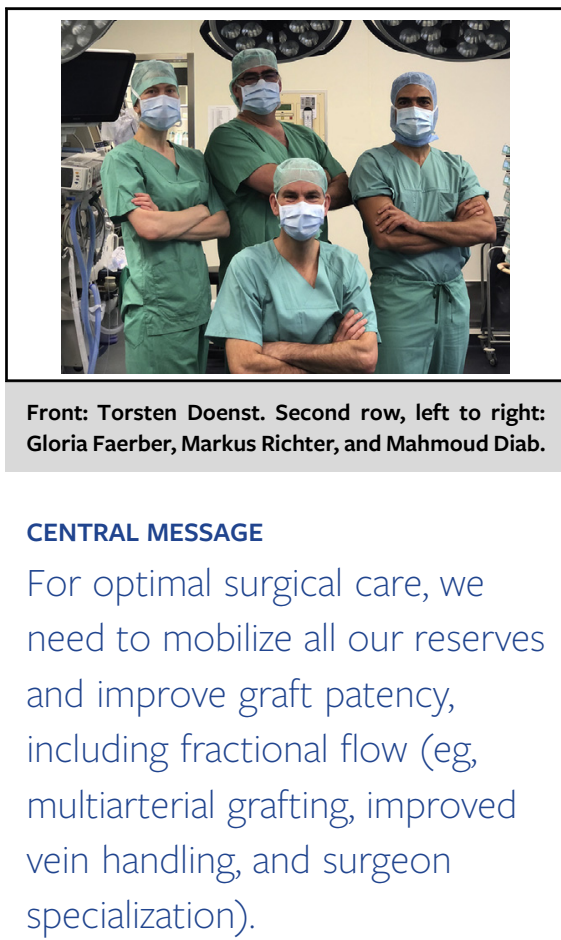

emerges with increasing risks for new myocardial infarctions. ${ }^{4}$

This effect requires patent bypass grafts; however, graft occlusions are common (up to $50 \%$ at 10 years $^{5}$ ). Thus, it may be time to mobilize our reserves to improve graft patency, including multiarterial grafting, surgeon specialization, and/or improved vein harvesting and handling techniques. ${ }^{6-9}$ Our current decision making for PCI or $\mathrm{CABG}$ is based on outcomes from the CABG trial, with patients not always having received our best.

The collateralization hypothesis would require all diseased territories to be grafted. However, besides surgical technicalities, graft patency is also affected by the flow relevance of coronary lesions. Fractional flow reserve (FFR) assesses the functional flow relevance of coronary lesions and has improved outcomes in PCI (primarily by reducing the need for re-revascularization). In this issue of the Journal, Glineur and colleagues ${ }^{10}$ elegantly review the value of FFR for CABG. For fully arterial CABG, it indeed allows the prediction of graft occlusions. At an FFR value $<0.78,97 \%$ of grafts were perfect at 6 months. At higher values, the risk of occlusion increased, depending on graft targets (circumflex or right) and configuration (single vs sequential). 
Two findings appear to be most important in this context. First, the detected graft occlusions were clinically silent. Thus, grafting a diseased vessel with a $50 \%$ risk of occlusion would still provide infarct protection in the other $50 \%$ without adding harm. Second, vein grafts do not appear to be as sensitive to competitive flow, suggesting that other mechanisms may be more relevant for graft failure. Thus, applying strategies to improve vein patency, such as no-touch techniques ${ }^{8}$ or external stenting, ${ }^{9}$ may be attractive options in case veins are required.

Glineur and coauthors conclude that FFR should not be used to decide between PCI and CABG. However, it can be used to improve graft type selection and thereby enhance our ability to provide more patients with patent grafts. On the battlefield of invasive CAD therapy, graft patency is key. ${ }^{4}$ Therefore, it is time to mobilize all our reserves, with and without fractional flow.

\section{References}

1. Cohan D, Brown E. Is the tide turning on the "grubby" affair of EXCEL and the European guidelines? 2020. Available at: https://www.medscape.com/ viewarticle/939944. Accessed September 11, 2020.
2. Figulla HR, Lauten A, Maier LS, Sechtem U, Silber S, Thiele H. Percutaneous coronary intervention in stable coronary heart disease: is less more? Dtsch Arztebl Int. 2020;117:137-44.

3. Head SJ, Milojevic M, Daemen J, Ahn JM, Boersma E, Christiansen EH, et al. Mortality after coronary artery bypass grafting versus percutaneous coronary intervention with stenting for coronary artery disease: a pooled analysis of individual patient data. Lancet. 2018;391:939-48.

4. Doenst T, Haverich A, Serruys P, Bonow RO, Kappetein P, Falk V, et al. PCI and $\mathrm{CABG}$ for treating stable coronary artery disease: JACC review topic of the week. J Am Coll Cardiol. 2019;73:964-76.

5. Gaudino M, Antoniades C, Benedetto U, Deb S, Di Franco A, Di Giammarco G, et al. Mechanisms, consequences, and prevention of coronary graft failure. Circulation. 2017;136:1749-64.

6. Gaudino M, Benedetto U, Bakaeen F, Rahouma M, Tam DY, Abouarab A, et al. Off- versus on-pump coronary surgery and the effect of follow-up length and surgeons' experience: a meta-analysis. J Am Heart Assoc. 2018;7:e010034.

7. Rosati CM, Torregrossa G, Balkhy HH, Puskas JD. Dedicated training in advanced coronary surgery: need and opportunity. J Thorac Cardiovasc Surg. April 18, 2020 [Epub ahead of print].

8. Samano N, Geijer H, Liden M, Fremes S, Bodin L, Souza D. The no-touch saphenous vein for coronary artery bypass grafting maintains a patency, after 16 years, comparable to the left internal thoracic artery: a randomized trial. J Thorac Cardiovasc Surg. 2015;150:880-8.

9. Taggart DP, Webb CM, Desouza A, Yadav R, Channon KM, De Robertis F, et al. Long-term performance of an external stent for saphenous vein grafts: the VEST IV trial. J Cardiothorac Surg. 2018;13:117.

10. Glineur D, Chong AY, Grau J. What should be the role of fractional flow reserve measurement in patients undergoing coronary artery bypass grafting? J Thorac Cardiovasc Surg Open. 2021;5:74-9. 